\title{
Levels and distributions of polychlorinated naphthalenes in sewage sludge of urban wastewater treatment plants
}

\author{
GUO Li, ZHANG Bing, XIAO Ke, ZHANG QingHua \& ZHENG MingHui ${ }^{\dagger}$ \\ State Key Laboratory of Environmental Chemistry and Ecotoxicology, Research Center for Eco-Environmental Sciences, Chinese \\ Academy of Sciences, Beijing 100085, China
}

Over seventy congeners of polychlorinated naphthalenes (PCNs) in sewage sludge of 8 urban wastewater treatment plants (WWTPs) in Beijing were analyzed by isotope dilution, and high resolution gas chromatography/high resolution mass spectrometry (HRGC/HRMS) method. The total PCN concentrations determined in the samples range from 1.48 to $28.21 \mathrm{ng} / \mathrm{g} \mathrm{dw}$ (dry weight) with TEQ concentrations of $0.11-2.45 \mathrm{pg} / \mathrm{g} \mathrm{dw}$. These levels were lower than those found in other regions. DiCNs and TrCNs were the most dominant homologues of PCNs. The similar congener profiles in all the samples suggest the similarity in certain sources. Contamination from industrial input might be the most significant source of PCNs in the sludges in this study, and thermal processes such as waste incineration and coal combustion may be another source of the PCNs contamination.

sewage sludge, polychlorinated naphthalenes (PCNs), high resolution gas chromatography/high resolution mass spectrometry (HRGC/ HRMS), contributions, profiles

Polychlorinated naphthalenes (PCNs) are a group of compounds based on a naphthalene ring with one to eight chlorine substitutions, which have 75 possible PCN congeners. They have similar physical and chemical properties and similar usages with polychlorinated biphenyls (PCBs). Before 1980s, technical mixtures of PCNs were produced on a technical scale by a wide variety of industries and had specific uses. For example, Halowax, one of the major PCN products, was produced by Koppers Co. USA, and voluntarily ceased in 1977. These products were widely used in industrials: capacitor and transformer fluids, cable insulation and flame retardants, cable-covering compositions, lubricants, plasticizers, casting materials for alloys, etc. Additionally, PCNs were unintentionally released as trace contaminants in the processes such as waste incineration, metal refining and chemical industries ${ }^{[1-3]}$. In recent years, many studies have shown that PCNs are one of classes of persistent organic pollutants (POPs) that are ubiquitous in the environment ${ }^{[4]}$. Due to their potential for toxicity, bioaccumulation and long-range atmospheric transport, PCNs were selected by the United Nations Economic Commission for Europe (UN-ECE) as a candidate for POPs Proctocol in $1998^{[5]}$. Studies on the levels of PCNs in the environment are of broad interest. To date, PCNs have been measured in air ${ }^{[6]}$, soil ${ }^{[7]}$, sediment and biota ${ }^{[8,9]}$. Compared with other POPs, such as PCBs and dioxins, however, knowledge on levels, sources and effects of these compounds in the environment is very limited ${ }^{[10]}$.

Municipal sewage sludges were generated as the solid waste products from the sedimentation of the suspended solids during the wastewater (including domestic and industrial wastewater in small quantity) treatment at the wastewater treatment plants (WWTPs) and very complicated in composition. Sludge is often regarded as a

Received August 31, 2007; accepted November 14, 2007 doi: 10.1007/s11434-008-0129-4

${ }^{\dagger}$ Corresponding author (email: zhengmh@rcees.ac.cn)

Supported by the National Natural Science Foundation of China (Grant Nos. 20677070 and 20621703) 
potential manure resource, because it contains high proportions of organic matter and abundant plant nutrients. However, it also consists of heavy metals and various persistent organic pollutants. It would easily cause the secondary pollution if coming into the environment without good treatment. Now a lot of studies have been carried out to investigate the possible environmental hazards of heavy metals ${ }^{[11,12]}$. Unfortunately, however, relatively limited investigations have been reported on persistent organic pollutants of sewage sludg $\mathrm{e}^{[13]}$. In the present study, levels and sources of PCNs in sewage sludge at 8 wastewater treatment plants in Beijing were investigated to provide credible data and basic scientific information for the reasonable disposal and uses of municipal sewage sludge, which were also helpful to better understanding the general characters of organic contamination in full scale. To our knowledge, there have been quite limited studies on PCNs in sewage sludge ${ }^{[14]}$, and little information of PCNs on sludge available in China.

To the best of our knowledge, no study on PCNs by isotope dilution-HRGC/HRMS has been conducted in China. With this method, PCNs (from MoCNs to OCN) in sewage sludge of 8 urban wastewater treatment plants in Beijing have been investigated. Further discussions have been made on PCNs contamination, patterns and possible sources of the sewage sludge.

\section{Experimental}

\subsection{Standards and reagents}

All solvents were of pesticide residue grade and purchased from Tedia Co. (USA). Silica Gel (100-200 mesh) was obtained from Qingdao Haiyang Chemical Co. China. Permeable gel: SX-3 Bio-Beads (200-400 mesh, Bio-Rad Co. USA).

Native and ${ }^{13} \mathrm{C}$ isotope-labeled PCN congener standards were purchased from Cambridge Isotope Labora- tories, USA, whereas technical mixtures of Halowax 1014 were obtained from Accustandard Co. USA.

\subsection{Sample collection and pretreatment}

Sewage sludge samples were collected from WWTPs in Beijing in May, 2007 and their related details are shown in Table 1. Samples were packed in aluminum foil, then directly delivered to the laboratory and stored in a refrigeratory. Before analysis, sludge samples were freeze-dried for about $60 \mathrm{~h}$ and homogenized.

\subsection{Extraction and clean-up}

Approximately $2-3 \mathrm{~g}$ dry weight (dw) sludge samples were mixed with appropriate anhydrous sodium sulphate in a glass thimble until becoming homogeneous. The samples were spiked with a mixture of $1 \mathrm{ng}{ }^{13} \mathrm{C}$-labeled PCN internal standards (including CN-27, 42, 52, 67, 73 and 75 ), and Soxhlet-extracted for $24 \mathrm{~h}$ with toluene.

The extracts were concentrated and solvent-exchanged to $n$-hexane for further clean-up as follows: a multi-layer silica column (from bottom to top: $1 \mathrm{~g}$ activated silica, $2 \mathrm{~g} \mathrm{AgNO}_{3}$ silica, $1 \mathrm{~g}$ activated silica, $3 \mathrm{~g}$ basic silica, $1 \mathrm{~g}$ activated silica, $8 \mathrm{~g}$ acidic silica, $1 \mathrm{~g}$ activated silica and $2 \mathrm{~cm}$ anhydrous sodium sulphate) was used and eluted with $100 \mathrm{ml} n$-hexane. The second column was a permeable gel column (GPC) packed with 30 g SX-3 Bio-Beads. Before loading the extracts, the column was pre-washed with $50 \mathrm{~mL} 50 \%$ dichloromethane (DCM) in $n$-hexane. Samples were eluted with $120 \mathrm{~mL} 50 \% \mathrm{DCM}$ in $n$-hexane, the first $50 \mathrm{~mL}$ effluent was discarded and the following $70 \mathrm{~mL}$ effluent was collected. The extracts were further concentrated and passed through a column with $8 \mathrm{~g}$ basic alumina and 2 $\mathrm{cm}$ anhydrous sodium sulphate for further purification. Samples were then eluted with $80 \mathrm{~mL} 5 \%$ DCM in $n$-hexane. The fractions were concentrated to about 20 $\mu \mathrm{L}$ with gentle stream of nitrogen. Prior to injection, a ${ }^{13} \mathrm{C}$-labeled injection standard (CN-64) was added for calculation of recovery.

Table 1 Major characteristics of the wastewater treatment plants (WWTPs)

\begin{tabular}{|c|c|c|c|c|}
\hline WWTPs & Wastewater type & Secondary treatment & Capacity $\left(\mathrm{m}^{3} / \mathrm{d}\right)$ & Digestion treatment \\
\hline S1 & domestic & OD & $2.0 \times 10^{5}$ & - \\
\hline $\mathrm{S} 2$ & domestic & AS & $4 \times 10^{4}$ & aerobic \\
\hline $\mathrm{S} 3$ & domestic & AS & $2.0 \times 10^{5}$ & $\mathrm{~A}^{2} / \mathrm{O}$ \\
\hline $\mathrm{S} 4$ & domestic & AS & $8 \times 10^{4}$ & anaerobic \\
\hline S5 & domestic & AS & $6.0 \times 10^{5}$ & $\mathrm{~A}^{2} / \mathrm{O}$ \\
\hline S6 & domestic & AS & $1.0 \times 10^{5}$ & anaerobic \\
\hline S7 & industrial/domestic (1/1) & AS & $5.0 \times 10^{5}$ & anaerobic \\
\hline S8 & industrial/domestic $(1 / 1)$ & AS & $5.0 \times 10^{5}$ & anaerobic \\
\hline
\end{tabular}

AS, activated sludge; OD, oxidation ditch. 


\subsection{Instrumental analysis}

HRGC-HRMS measurements were carried out with a double Trace GC coupled with DFS mass spectrometer (Thermo Electron Corporation, USA) on a resolution of approximately 10000 with $\mathrm{EI}^{+}$mode $(45 \mathrm{eV})$. HRMS was operated in selected ion monitoring (SIM) mode and the ion source temperature was $270^{\circ} \mathrm{C}$.

A DB-5 $(60 \mathrm{~m} \times 0.25 \mathrm{~mm} \times 0.25 \mu \mathrm{m}, \mathrm{J} \& \mathrm{~W})$ capillary column was used for the determination of $\mathrm{PCN}$ congeners. The column temperature initiated at $80^{\circ} \mathrm{C}(2 \mathrm{~min})$, and increased to $180^{\circ} \mathrm{C}(1 \mathrm{~min})$ at $20^{\circ} \mathrm{C} / \mathrm{min}, 280^{\circ} \mathrm{C}$ at $2.5^{\circ} \mathrm{C} / \mathrm{min}$, and $290^{\circ} \mathrm{C}(5 \mathrm{~min})$ at $10^{\circ} \mathrm{C} / \mathrm{min}$. The injector and interface temperatures were 260 and $290^{\circ} \mathrm{C}$, respectively. The carrier gas was helium at $1 \mathrm{~mL} / \mathrm{min}$. Injection volume was $1 \mu \mathrm{L}$ in splitless mode.

\subsection{Quality assurance and quality control}

Quality assurance and quality control of the trace PCNs determination are of great importance. Before extraction, the whole Soxhlet apparatus were pre-extracted for over 6 $\mathrm{h}$ with $250 \mathrm{~mL}$ toluene. A method blank was monitored to evaluate the contamination. The results were free of PCN homologues except MoCNs and DiCNs, which were $10 \%$ lower than the lowest sample concentrations. All the sample concentrations in this study were not corrected with blank values.

Several native standards (PCN-13, 27, 42, 52, 54, 64, 67, 70, 73, and 75) and technical Halowax 1014 together with ${ }^{13} \mathrm{C}$-labeled standards were used to identify the elution pattern of PCN congeners. The peak identification was subsequently performed by comparison between the peaks' retention time and the appropriate PCN chromatographic data published ${ }^{[15,16]}$. The peaks of PCN congeners could be identified by relative retention time compared to standards and were quantified if isotope ratios of the two monitored ions for each compound were within $15 \%$ of theoretical value.

The recovery in samples was obtained using the ${ }^{13} \mathrm{C}$-labeled PCNs standards to ensure the repeatability of the results. The average recovery of ${ }^{13} \mathrm{C} \mathrm{CN}-27,42$, $52,67,73$ and 75 in sewage sludge was $89.0 \%, 84.9 \%$, $95.4 \%, 97.5 \%, 91.4 \%$ and $64.1 \%$, respectively. The limit of detection (LOD) for individual congener was defined by a signal to noise ratio of $3: 1$. The concentrations of PCN congeners in samples were destined for LOD values when they were lower than LOD values.

\section{Results and discussion}

\subsection{PCN concentrations in sludge}

Concentrations of PCNs in sewage sludge of WWTPs are shown in Figure 1. $\Sigma \mathrm{PCNs}$ concentrations range from 1.48 to $28.21 \mathrm{ng} / \mathrm{g} \mathrm{dw}$ with a mean value of 7.69 $\mathrm{ng} / \mathrm{g} \mathrm{dw}$. Relatively high concentrations of $\Sigma \mathrm{PCNs}$ are found in samples S7 (27.09 $\mathrm{ng} / \mathrm{g} \mathrm{dw})$ and S8 (28.21 ng/g $\mathrm{dw}$ ), which were about $10-20$ times higher than other sludge samples. S7 and S8 plants with a 50\% input of industrial effluent have the highest levels of $\Sigma$ PCNs, probably because PCNs as by-products directly contained in the equipments in some industrial processes entered the wastewater in the WWTPs and subsequently deposited into sewage sludge. By contrast, the other 6 plants with a high input of domestic effluent have low concentrations of $\Sigma \mathrm{PCNs}$, ranging from 1.48 to 2.57 $\mathrm{ng} / \mathrm{g} \mathrm{dw}$ with a mean value of $2.04 \mathrm{ng} / \mathrm{g} \mathrm{dw}$. Compared with some other reports, these values were at the same level as the background concentrations (about $1 \mathrm{ng} / \mathrm{g} \mathrm{dw}$ ) in sediments ${ }^{[17-19]}$. This may indicate that point sources (industrial effluent discharges) are the most important contributors of PCNs to the sludge. The results, in principle, demonstrate that wastewater inputs significantly affect the contaminant levels of PCNs in sewage sludge. PCN concentrations are relatively low in samples dominated by domestic effluents of Beijing but obviously elevated in samples with high inputs of industrial effluents.

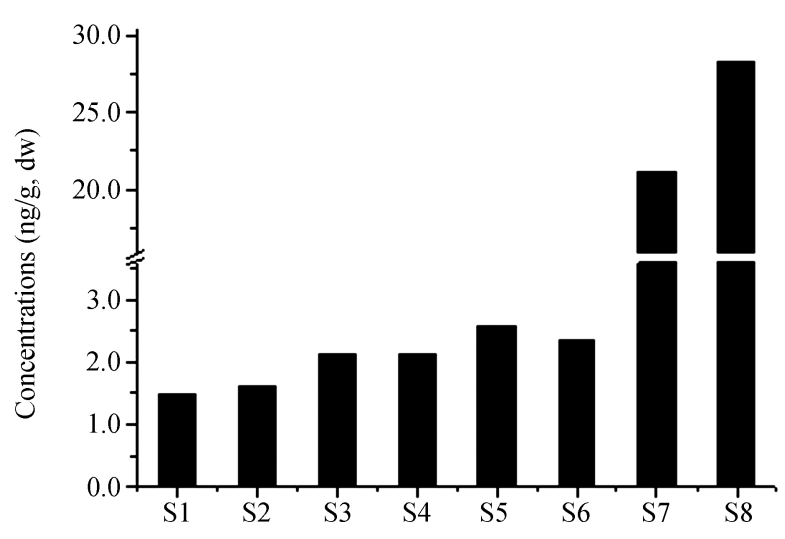

Figure $15 \mathrm{PCN}$ concentrations in sewage sludge.

Stevens et al. ${ }^{[14]}$ investigated PCNs as well as PAHs, PCBs, and synthetic musks concentrations in the digested sludge from 14 UK WWTPs. Although only 35 PCN congeners were analyzed, total PCN concentrations 
ranged from 50 to $190 \mathrm{ng} / \mathrm{g} \mathrm{dw}$, which were significantly higher than PCN values in the present study. In addition, Meijer et al. ${ }^{[20]}$ reported $\Sigma$ PCN concentrations of about $250 \mathrm{ng} / \mathrm{g}$ in the sludge, a factor of almost 40 times higher than the one measured in soil at the same period. Moreover, the one-time sludge application resulted in elevated soil residues that were 1.5-6 times higher than the control plot over the time series. In comparison with those reports on PCN levels, the current data are at rather low level.

\subsection{PCN homologue profiles}

As shown in Figure 2, the homologue profiles are similar in all sewage sludge samples independent of wastewater types. It means that PCNs in these samples from either industrial effluent or domestic effluent have similar homologue patterns. Moreover, careful observation could find that the lower chlorinated congeners MoCNsTeCNs, accounting for $82.6 \%-91.2 \%$ of the total PCNs, are characteristically predominant in all sludge samples. DiCNs and TrCNs are the most dominant homologues of PCNs in sludge. For samples $\mathrm{S} 1-\mathrm{S} 6$, TrCNs are the greatest contributor with the ratio ranging from $31.5 \%$ to $41.0 \%$ of the total PCN concentrations. But for samples S7 and S8, DiCNs are the dominant homologue, accounting for $47.1 \%$ and $44.6 \%$, respectively. Although with lower concentrations, higher chlorinated homologues (PeCNs-OCN) were detected in all samples. Generally, the PCN homologue profiles (TeCNs-HpCNs) in sludge of this study decrease in concentration from the lower to the higher chlorinated homologues. Similar trend was reported by Lundgren et al. ${ }^{[19]}$ in surface sediment samples from the north part of Baltic Sea.
Through the ananlysis on TrCNs-HpCNs in the one-time urban sewage sludge and the sludge-amended soil, Meijer et al. ${ }^{[20]}$ found that both $\mathrm{TrCNs}$ and $\mathrm{TeCNs}$ contributed more than $86 \%$ to the concentrations of $\Sigma$ PCNs. PCN profiles in this study are similarly dominated by lower chlorinated homologues. Possible reasons are that some technical products containing lower chlorinated homologues of PCNs with the relatively high water solubility were prone to enter urban wastewater. Deposition of lower chlorinated PCNs in sludge from the process of wastewater treatment might be considered as the main contributor. On the other hand, the degradation of some PCN congeners, especially the higher chlorinated congeners capable of degrading to the lower ones, may alter the compositions of PCN homologues. In addition, atmospheric deposition and other sources may also affect the profiles of PCN homologues.

\subsection{PCN congener patterns and possible sources}

Over 70 PCN congeners of 42 single peaks and 16 peaks in pairs or triplicate were identified on the DB-5 column by isotope dilution-HRGC/HRMS method. Most of PCN congeners could be detected in sewage sludge samples. Generally, samples S1-S6 have similar patterns of PCN congeners except for a little variance with samples S7 and S8. It indicates that the sources of effluent have little effection on PCN congener patterns. $\mathrm{CN}-5 / 7$ and $\mathrm{CN}-24 / 14$ seem to be the most predominant congeners not only to the corresponding homologues, but also to the total PCN concentrations in all samples. The contributions of $\mathrm{CN}-5 / 7$ in $\mathrm{S} 7$ and S8 sludge were almost twice as high as those in S1-S6 ones. However, the contributions of $\mathrm{CN}-24 / 14$ to the total PCNs in $\mathrm{S} 7$ and $\mathrm{S} 8$ sludge are almost twice as low as those in $\mathrm{S} 1-\mathrm{S} 6$ ones.

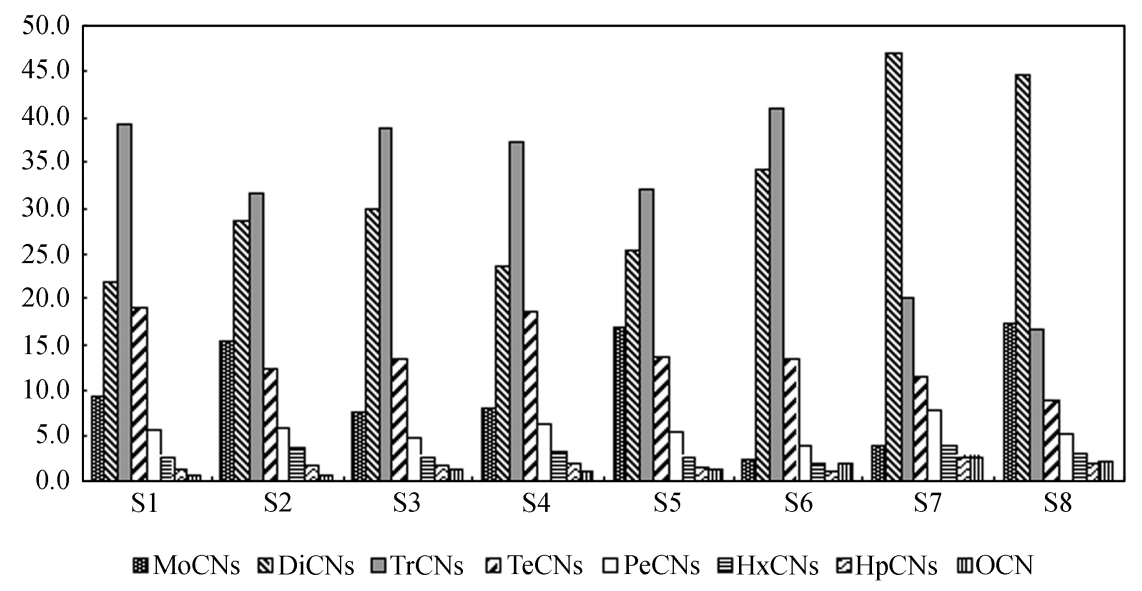

Figure 2 PCN homologue profile of the sewage sludge samples ( $\%$ of the total). 
In addition, $\mathrm{CN}-6 / 12,3$ in $\mathrm{DiCNs}$, and $\mathrm{CN}-13,23$ in TrCNs were also the dominant congeners in sludge. The higher chlorinated congeners of PCNs are in similar patterns and dominant with $\mathrm{CN}-52 / 60$ in PeCNs, $\mathrm{CN}-66 / 67$ in $\mathrm{HxCNs}$ and $\mathrm{CN}-73$ in HpCNs.

PCNs contamination sources in sludge of WWTPs are complicated. The two congeners of MoCNs could be detected in all sludge samples. In samples $\mathrm{S} 1-\mathrm{S} 4$, and $\mathrm{S} 6$, the contents of $\mathrm{CN}-2$ are higher than or equal to $\mathrm{CN}-1$ contents. This is in agreement with the ratios in fly ash from a municipal waste incinerator ${ }^{[16]}$, but quite different with that in Halowax mixtures, which is dominated by $\mathrm{CN}-1$. CN-44, 39, 51, 54 and 70 are detected in sludge samples with low concentrations, while these congeners were not present in Halowax mixtures, therefore, they are considered as combustion-related indictor congeners ${ }^{[16,21]}$. Moreover, Järnberg et al. ${ }^{[21]}$ found an increase in CN-52/60, 66/67 and 73 in fly ash and a chloralkali sample compared to the Halowax 1014. Furthermore, in the present study, the ratio of CN-73/CN-74 in HpCNs with the range of $1.8-3.1$ is close to that described by Järnberg et al. ${ }^{[22]}$ and Gevao et al. ${ }^{[23]}$ for contaminations from combustion sources, but much higher than $\mathrm{CN}-73 / \mathrm{CN}-74$ ratios with the range of $0.2-0.4$ in Halowax mixtures ${ }^{[24]}$. Additionally, domestic burning of coal and wood also contribute to the emission of $\mathrm{PCNs}^{[3]}$. In Beijing, a number of steel works and power plants may cause the contamination of PCNs. The results described above hint that incineration or combustion sources might be one of the sources of PCNs in Beijing sludge. PCNs emitted from thermal processes may enter WWTPs by direct discharge or/and atmospheric deposition.

Meanwhile, lower chlorinated congeners dominated by $\mathrm{CN}-5 / 7$ and $\mathrm{CN}-24 / 14$ have great contributions to total PCNs in the sewage sludge samples. These congeners were also the typical congeners in some Halowax technical mixtures ${ }^{[24]}$. The lower chlorinated PCN technical mixtures were widely used in daily life predominantly as lubricants, plasticizers and casting materials for alloys (http://www.nicnas.gov.au/publications/car/ other/S48_PCN_July02.pdf). As a result, some Halowax mixtures with lower chlorinated congeners might be the major source of PCNs in sludge. To our knowledge, however, no PCN technical products were produced and the used data of Halowax mixtures are very sparse. In consequence, it is difficult to point out the sources di- rectly. In addition, atmospheric deposition and other sources may also be the PCN sources in sludge ${ }^{[19]}$.

\subsection{PCN toxic equivalents (TEQs)}

Only a few studies have been reported on PCNs toxicities ${ }^{[25,26]}$. In this study, relative potency factors (RPFs) summarized by Noma ${ }^{[24]}$ (Table 2) were used to calculate the PCN-TEQs in sewage sludge. The PCN-TEQs concentrations were $0.11-2.45 \mathrm{pg} \mathrm{TEQ} / \mathrm{g}$ dw with a mean value of $0.72 \mathrm{pg} T E Q / \mathrm{g} \mathrm{dw}$, which was quite lower than the maximum permissible TEQ concentrations (100 pg TEQ/g dw for polychlorinated dibenzo- $p$-dioxins and dibenzofurans) in sludge for land application of China (Discharge standard of pollutants for municipal wastewater treatment plant, GB18918-2002).

Table 2 Dioxin-like PCN congeners and their relative potency factors $(\mathrm{RPFs})^{[24]}$

\begin{tabular}{cccc}
\hline PCN congeners & RPF & PCN congeners & RPF \\
\hline $\mathrm{CN}-2$ & $1.8 \times 10^{-5}$ & $\mathrm{CN}-57$ & $1.6 \times 10^{-6}$ \\
$\mathrm{CN}-1$ & $1.7 \times 10^{-5}$ & $\mathrm{CN}-56$ & $4.6 \times 10^{-5}$ \\
$\mathrm{CN}-4$ & $2.0 \times 10^{-8}$ & $\mathrm{CN}-66 / 67$ & $2.5 \times 10^{-3}$ \\
$\mathrm{CN}-5 / 7$ & $1.8 \times 10^{-8}$ & $\mathrm{CN}-64 / 68$ & $1.0 \times 10^{-3}$ \\
$\mathrm{CN}-10$ & $2.7 \times 10^{-5}$ & $\mathrm{CN}-69$ & $2.0 \times 10^{-3}$ \\
$\mathrm{CN}-48 / 35$ & $2.1 \times 10^{-5}$ & $\mathrm{CN}-71 / 72$ & $3.5 \times 10^{-6}$ \\
$\mathrm{CN}-38 / 40$ & $8.0 \times 10^{-6}$ & $\mathrm{CN}-63$ & $2.0 \times 10^{-3}$ \\
$\mathrm{CN}-50$ & $6.8 \times 10^{-5}$ & $\mathrm{CN}-70$ & $1.1 \times 10^{-3}$ \\
$\mathrm{CN}-54$ & $1.7 \times 10^{-4}$ & $\mathrm{CN}-73$ & $3.0 \times 10^{-3}$ \\
\hline
\end{tabular}

In all sludge samples, the contribution patterns of dioxin-like PCN congeners to PCN-TEQs are similar as shown in Figure 3. This distribution, in combination

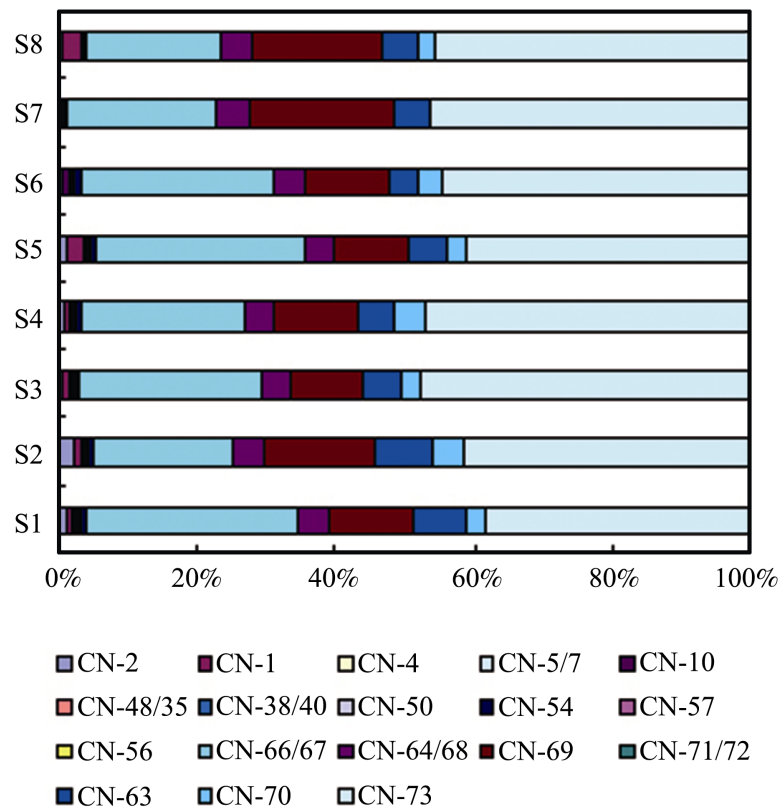

Figure 3 Contribution of dioxin-like PCN congeners to PCN-TEQs. 
with the homologue and congener profiles described above, seems to indicate that there is a great chance to have similar sources of PCNs.

$\mathrm{HpCN}-73$ is the predominant congener to PCN-TEQs among the dioxin-like congeners of PCNs, with relative abundance of $38 \%-48 \%$, followed by $\mathrm{HxCN}-66 / 67$ $(20 \%-30 \%)$ and then HxCN-69 $(10 \%-21 \%)$ in most samples. Furthermore, it was frequently reported that they were remarked as the characteristic $\mathrm{CN}$ congeners related to combustion.

\section{Conclusions}

The results indicate that PCNs are ubiquitous in urban

1 Iino F, Imagawa T, Takeuchi M, et al. De novo synthesis mechanism of polychlorinated dibenzofurans from polycyclic aromatic hydrocarbons and the characteristic isomers of polychlorinated naphthalenes. Environ Sci Technol, 1999, 33: 1038-1043

2 Imagawa $\mathrm{T}$, Lee $\mathrm{C}$ W. Correlation of polychlorinated naphthalenes with polychlorinated dibenzofurans formed from waste incineration. Chemosphere, 2001, 44: 1511- 1520

3 Lee R G M, Coleman P, Jones J L, et al. Emission factors and importance of PCDD/Fs, PCBs, PCNs, PAHs and PM10 from the domestic burning of coal and wood in the U.K. Environ Sci Technol 2005, 39: 1436-1447

4 Falandysz J. Polychlorinated naphthalenes: an environmental update. Environ Pollut, 1998, 101: 77-90

5 Lerche D, Plassche E van de, Schwegler A, et al. Selecting chemical substances for the UN-ECE POP protocol. Chemosphere, 2002, 47: $617-630$

6 Harner T, Lee R G M, Jones K. Poychlorinated naphthalenes in the atmosphere of the United Kingdom. Environ Sci Technol, 2000, 34: $3137-3142$

7 Wyrzykowska B, Hanari N, Orlikowska A, et al. Polychlorinated biphenyls and -naphthalenes in pine needles and soil from Poland-Concentrations and patterns in view of long-term environmental monitoring. Chemosphere, 2007, 67: 1877-1886

8 Kannan K, Imagawa T, Yamashita N, et al. Polychlorinated naphthalenes in sediment, fishes and fish-eating waterbirds from Michigan waters of the Great Lakes. Organohalogen Compd, 2000, 47: 13-16

9 Llobet J M, Falcó G, Bocio A, et al. Human exposure to polychlorinated naphthalenes through the consumption of edible marine species. Chemosphere, 2007, 66: 1107-1113

10 Brack W, Kind T, Schrader S, et al. Polychlorinated naphthalenes in sediments from the industrial region of Bitterfeld. Environ Pollut, 2003, 121: $81-85$

11 Chen T, Huang Q, Gao D, et al. Heavy metal concentrations and their decreasing trends in sewage sludges of China. Acta Scientiae Cricumsta-Ntiae (in Chinese), 2003, 23: 561-569

12 García-Delgado M, Rodríguez-Cruz M S, Lorenzo L F, et al. Seasonal and time variability of heavy metal content and of its chemical forms in sewage sludges from different wastewater treatment plants. Sci Total Environ, 2007, 382: 82-92

13 Wang Y, Zhang Q, Lü J, et al. Polybrominated diphenyl ethers and organochlorine pesticides in sewage sludge of wastewater treatment plants in China. Chemosphere, 2007, 68: 1683-1691

14 Stevens J L, Northcott G L, Stern G A, et al. PAHs, PCBs, PCNs, organochlorine pesticides, synthetic musks, and polychlorinated sewage sludge of WWTPs in Beijing. Although higher levels have been found in samples S7 and S8, the average concentrations of total PCNs in all sludge were lower than those reported in the past. The dominant homologues of PCNs were DiCNs and TrCNs, which might come from the technical mixtures with lower chlorinated congeners. PCN homologue and congener patterns indicated that thermal processes such as waste incineration and coal combustion might be the other sources of the PCNs contamination. Those PCNs may enter WWTPs by direct discharge or/and atmospheric deposition. TEQ values of PCNs in sewage sludge ranged from 0.11 to $2.45 \mathrm{pg}$ TEQ/g dw. CN-66/67, 73 and 69 were the major contributors to PCN-TEQs.

$n$-alkanes in U.K. sewage sludge: Survey results and implications Environ Sci Technol, 2003, 37, 462-467

15 Abad E, Caixach J, Rivera J. Dioxin like compounds from municipal waste incinerator emissions: Assessment of the presence of polychlorinated naphthalenes. Chemosphere, 1999, 38(1): 109-120

16 Schneider M, Stieglitz L, Will R, et al. Formation of polychlorinated naphthalenes on fly ash. Chemosphere, 1998, 37:2055-2070

17 Pan J, Yang Y L, Xu Q, et al. PCBs, PCNs and PBDEs in sediments and mussels from Qingdao coastal sea in the frame of current circulations and influence of sewage sludge. Chemosphere, 2007, 66 1971- 1982

18 Yamashita N, Kannan K, Imagawa T, et al. Vertical profile of polychlorinated dibenzo-p-dioxins, dibenzofurans, naphthalenes, biphenyls, polycyclic aromatic hydrocarbons, and alkylphenols in a sediment core from Tokyo Bay, Japan. Environ Sci Technol, 2000, 34: $3560-3567$

19 Lundgren K, Tysklind M, Ishaq R, et al. Flux estimates and sedimentation of polychlorinated naphthalenes in the northern part of the Baltic Sea. Environ Pollut, 2003, 126: 93-105

20 Meijer S N, Harner T, Helm P A, et al. Polychlorinated naphthalenes in UK soils: time trends, markers of source, and equilibrium status. Environ Sci Technol, 2001, 35: 4205-4213

21 Järnberg, U, Asplund, L, de Wit C, et al. Distribution of polychlorinated naphthalene congeners in environmental and source-related samples. Arch Environ Contam Toxicol, 1997, 32: 232-245

22 Järnberg U, Asplund L, Egebäck A-L, et al. Polychlorinated naphthalene congener profiles in background sediments compared to a degraded halowax 1014 technical mixture. Environ Sci Technol, 1999, 33: $1-6$

23 Gevao B, Harner T, Jones K C. Sedimentary record of polychlorinated naphthalene concentrations and deposition fluxes in a dated lake core. Environ Sci Technol, 2000, 34: 33-38

24 Noma Y, Yamamoto T, Sakai S-I. Congener-Specific Composition of polychlorinated naphthalenes, coplanar PCBs, dibenzo-p-dioxins, and dibenzofurans in the halowax series. Environ Sci Technol, 2004, 38: $1675-1680$

25 Blankenship A L, Kannan K, Villalobos S A, et al. Relative potencies of individual polychlorinated naphthalenes and halowax mixtures to induce Ah receptor-mediated responses. Environ Sci Technol, 2000, 34: $3153-3158$

26 Villeneuve D L, Kannan K, Khim J S, et al. Relative potencies of individual polychlorinated naphthalenes to induce dioxin-Like responses in fish and mammalian in vitro bioassays. Arch Environ Contam Toxicol, 2000, 39: 273-281 